\title{
Guidelines for Age Determination of Silver Hake, Merluccius bilinearis, Using Otoliths
}

\author{
J. J. Hunt \\ Department of Fisheries and Oceans, Marine Fish Division \\ Biological Station, St. Andrews, New Brunswick, Canada E0G $2 \times 0$
}

\begin{abstract}
Age determination of silver hake, Merluccius bilinearis, based on interpretation of otoliths and the application of relevant ageing conventions and criteria, is reviewed. The results of several workshops on ageing of silver hake are summarized, and the effects of agerelated physiological factors, such as spawning, are considered in relation to guidelines for the consistent estimation of age. Growth curves and geographic variation in otolith morphology are discussed, and photographs of typical otoliths with interpretations of age are presented.
\end{abstract}

\section{Introduction}

Since 1962, an intensive fishery for silver hake in the Northwest Atlantic has yielded annual catches ranging up to 300,000 metric tons and averaging about 100,000 tons from the Scotian Shelf. Stocks have been managed by catch limitation since 1974 with separate total allowable catches for the Canadian and American continental shelf areas under the assumption that the populations in these areas are discrete. The nominal catch for the Northwest Atlantic in 1976, just prior to the extension of coastal state jurisdiction over fisheries to 200 miles, was 179,000 tons, but declined to 115,000 tons in 1977, due probably to mesh size restrictions, geographic limitation of fishing activity, and by-catch quotas. The silver hake catch on the Scotian Shelf in 1977 was 37,000 tons compared with 97,000 tons in 1976.

Biological sampling of commercial and research survey catches have provided considerable length and age data for this species. Historically, the age structure of the populations has been based on otolith interpretation, but recent comparision of age estimates have indicated some discrepancy between otolith readers (Anderson and Nichy, MS 1975). Since 1975, three ageing workshops (ICNAF MS 1976, MS 1977, MS 1978) and other biological studies (Hunt, 1978, 1979) have been completed, and this paper attempts to summarize the results of recent research and provide guidelines for determining age and associated growth parameters for silver hake in the Northwest Atlantic.

\section{Collection of Biological Samples}

A biological sample generally consists of a length frequency of at least 100 fish selected at random from the catch. During the process of measuring the fish, a stratified sample of one or two fish per centimeter length group by sex are retained for detailed examination. The requirement is that the length be measured from the tip of the snout to the mid-fork of the caudal fin (fork length). Differential growth between the sexes necessitates that length frequencies be recorded for males and females separately. Information on the location and date of capture should be as specific as possible.

Samples retained for detailed analysis are examined for length, weight, sex and maturity, and structures for use in age determination are removed, carefully labelled and stored for subsequent examination. Maturity is assigned on the basis of eight stages which apply to both sexes: immature (I), ripening 1 (II), ripening 2 (III), ripe (IV), spawning (V), spent (VI), recovering (VII), and resting (VIII). Scales are generally taken from the area ventral to the lateral line and within the radius of the pectoral fin and are stored dry in envelopes for subsequent mounting on glass slides or use in making plastic impressions. Two or more vertebrae, for comparative examination and estimation of age, are generally removed from the anterior section of the vertebral column and stored dry in envelopes. Otoliths are extracted by making a transverse cut through the skull just posterior to the eyes, taking care to avoid breaking the thin rostrum found in large specimens, washed in clean water and stored dry or wet, depending on the planned method of ageing. Dry storage is usually in paper envelopes on which the relevant sample data are recorded. Wet storage is in a $50-60 \%$ glycerin solution to which a small amount of thymol has been added as a preservative. Small vials with numbered tags are frequently used to hold the otoliths until examination.

Separation of the two very similar species, offshore hake, $M$. albidus, and silver hake, M. bilinearis, 
at the time of collection has proven to be difficult. Some characteristics of the two species were compared by Mombeck (1971), and keys presented by Leim and Scott (1966) allow separation based on gillraker and lateral-line scale counts. They indicate that $M$. albidus has less than 12 gillrakers on the first arch and more than 130 scales on the lateral line, whereas $M$. bilinearis has more than 14 gillrakers and less than 130 lateral line scales. Observation suggests that the relative size of the pupil appears larger in $M$. albidus and that this species may have a purple sheen posterior to the operculum in contrast to a gold sheen for $M$. bilinearis in the fresh condition. Also, offshore hake appears to reach a larger size than silver hake, and therefore all specimens greater than $50 \mathrm{~cm}$ in length should be closely examined to ensure correct identification. Otolith morphology is distinctly different for the two species in fish greater than $25 \mathrm{~cm}$, the otolith of $M$. albidus being broader and the rostrum less pronounced than in $M$. bilinearis (Fig. 1), but this characteristic becomes less distinct in fish smaller than $25 \mathrm{~cm}$ in length.

\section{M. albidus}

\section{M. bilinearis}

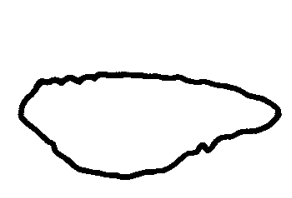

Fish

Length

$50 \mathrm{~cm}$
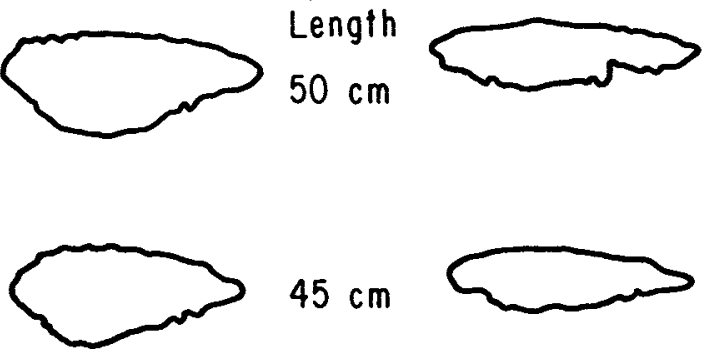

45

$\mathrm{cm}$
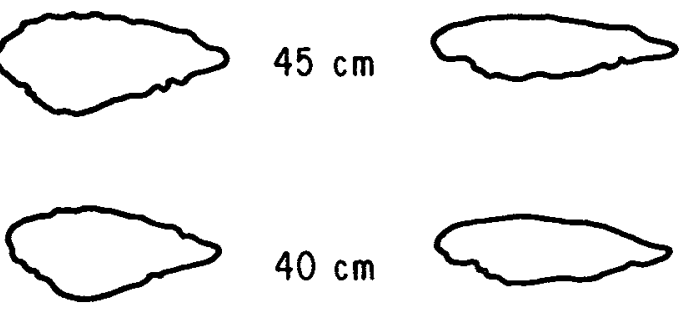

$40 \mathrm{~cm}$
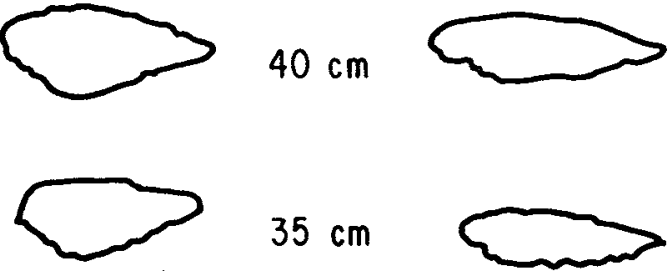

$35 \mathrm{~cm}$
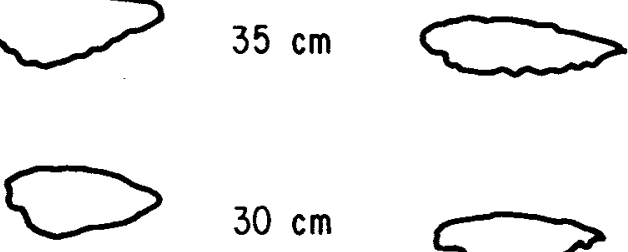

$30 \mathrm{~cm}$
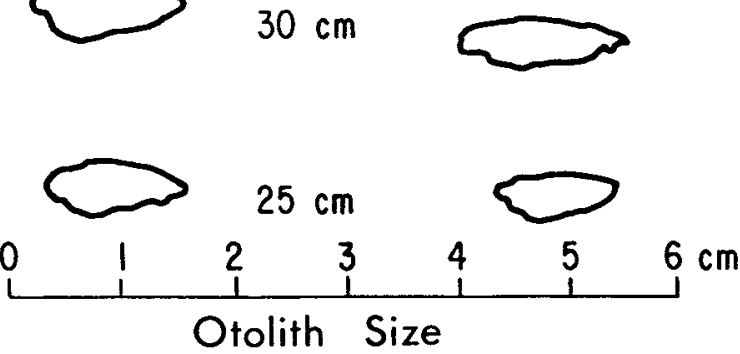

Fig. 1. Variation in otolith morphology of the two hake species, $M$. albidus and $M$. bilinearis.

\section{General Biology and Distribution}

Silver hake are encountered on the continental shelf areas of the Northwest Atlantic from Newfoundland to South Carolina, including the Gulf of St. Lawrence and Bay of Fundy. Two generalized stocks or populations appear to be separated by the Fundian Channel between Georges Bank and the Scotian Shelf. Scott (MS 1976) reviewed the summer distribution of silver hake on the Scotian Shelf based on research vessel survey data and found the species to be widespread, with specific areas of aggregation apparently related to temperature. Hunt (1978) also examined survey data for the Scotian Shelf and found a similar pattern of distribution with some variation during 1970-76 and evidence of segregation by size, the smaller fish $(<25 \mathrm{~cm})$ being generally closer to shore. Distribution off the USA coast appears to follow the edge of the continental shelf from Georges Bank southward to about $37^{\circ} \mathrm{N}$ latitude, with some concentration in the Gulf of Maine. Historically, commercial catches of silver hake in the Northwest Atlantic have been greatest in the first half of the year.

As previously noted, maturity of silver hake is classified into eight stages based on gonad development. Stages III to VIII indicate pre-spawning to post-spawning conditions and apply to mature fish, whereas stages I and II apply to immature individuals. Seasonal rates of development have not been studied, and it is possible that fish classified as immature early in the year may mature and spawn for the first time late in the season. The achievement of maturity in silver hake is generally related to length, and this relationship is usually represented by a sigmoid curve. Such a maturity curve (Fig. 2) was constructed from survey data for the Scotian Shelf in August of the years 1971-76 (Doubleday and Hunt, MS 1976). Data for

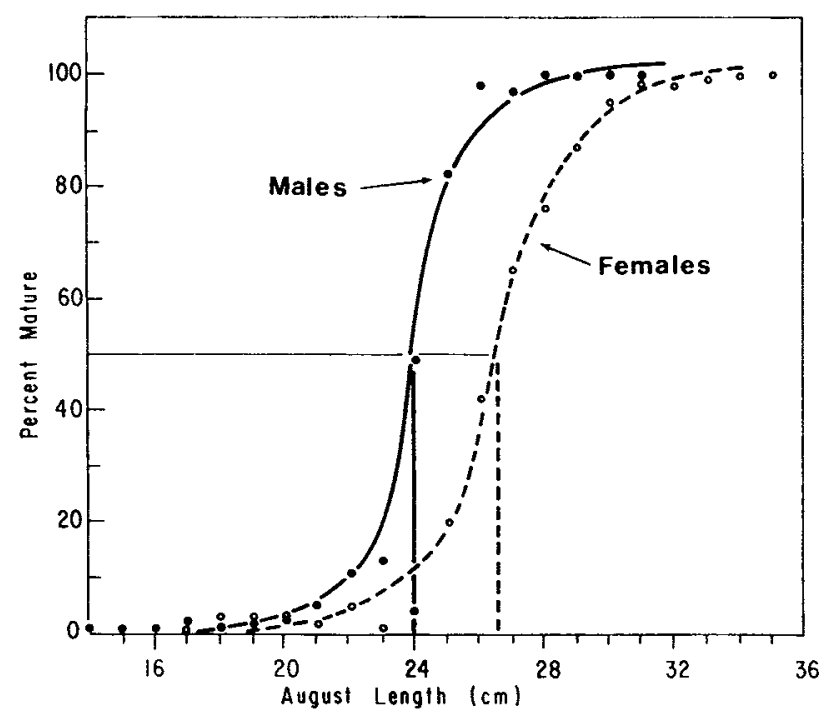

Fig. 2. Maturity ogives for silver hake on the Scotian Shelf, based on survey data for August in 1971-76. 
males and females were considered separately and the curves, fitted by eye show $50 \%$ maturity at 23.9 and 26.6 $\mathrm{cm}$ respectively. The smallest length at which an individual was observed to be maturing or mature was $18 \mathrm{~cm}$ and the largest immature fish was recorded as 34 $\mathrm{cm}$.

Spawning of silver hake occurs in summer and appears to be strongly influenced by water temperature. On the Scotian Shelf, fish in spawning condition may be observed from June to September, although peak spawning activity is generally in mid- to late July, as observed on Sable Island Bank (Sarnits and Sauskin, 1967; Noskov, MS 1976). Spawning occurs somewhat earlier on Georges Bank and farther southward off the USA coast with peak activity in midto late June. Annual variation occurs both in the peak and range of the spawning period, and this may have considerable influence on the growth of juveniles. Eggs of silver hake are pelagic and are generally found close to the major spawning locations. Knowledge of the distribution of eggs and larvae is limited but some information has been reported by Noskov et al. (MS 1978), and by A. C. Kohler (unpublished data, Biological Station, St. Andrews, New Brunswick) for August and September.

\section{Age Determination}

Estimation of age for silver hake is presently based almost exclusively on interpretation of otoliths for the presence of hyaline and opaque zones which are assumed to represent winter and summer growth periods respectively. Storage, preparation and examination of otoliths follow two different formats. One method consists of storing otoliths in a glycerin solution until they are examined for age, at which time they are viewed in glycerin or alcohol using reflected light at a magnification of 10-20 diameters. Hyaline zones appear translucent and the quality of the image is apparently quite good, but some masking of early growth in large fish may occur.

Otoliths stored dry become opaque and are unreadable as whole otoliths without further treatment. These otoliths are presently sectioned, using a macrotome, and the section or surface used for ageing. Otoliths mounted in paraffin wax require careful orientation to ensure cutting through the sulcus and at right angles to the long axis. A low-speed saw such as the Buehler Isomet with diamond grit blades has been found suitable for sectioning or cutting the otoliths in half. One blade is used to halve the otolith and two or more blades with appropriate separaters are used to obtain sections. The best results are obtained from sections less than $0.5 \mathrm{~mm}$ thick, but they are very fragile and care must be taken to ensure that they are not broken. The sections are examined using reflected light on a black background at a magnification of 30-50 diameters and may be covered with alcohol to reduce glare. Some success in reducing breakage has been achieved by mounting sections on black plexiglass trays using a solvent such as 1,2dichlorothane. Hyaline zones appear translucent under reflected light and early growth is usually quite clear.

When otoliths have been stored dry and sectioning is not convenient or possible, some alternatives may be considered in providing surfaces suitable of ageing. The otolith may be broken through the sulcus and the surfaces polished. Staining may further enhance the appearance of the zones. Whole otoliths, stored dry for relatively short periods ( $<1$ month), may be partially restored to a 'wet' condition by placing them in glycerine for 4-8 days, but otoliths stored dry for longer periods require additional treatment. Saturated saline $(\mathrm{NaCl})$ and 1-2\% nitric acid or ammonia solutions have been found to be effective. Immersion in a saline solution for at least 48 hours and transfer to $50 \%$ glycerin provides fair results, as does immersion in acid or alkaline solutions for about 5 minutes prior to examination. However, all of the post-sampling methods of treatment give only fair results, particularly for the older fish, and should only be considered when preferred techniques are not possible.

Staining and other enhancement of otolith zones have been attempted using various techniques including both chemical and mechanical treatment Some improvement in the appearance of the hyaline zones has been noted when the sections have been covered with oil of cloves a short time before ageing. Whole otoliths, which are to be sectioned or broken, may be immersed in a silver nitrate solution $(2 \mathrm{gm}$ silver nitrate in $25 \mathrm{ml}$ distilled water and $25 \mathrm{ml}$ ammonium hydroxide) in dark vials for $1-2$ weeks and then allowed to darken in sunlight for 3-5 days prior to sectioning. Numerous other staining processes, based on the different chemical composition of the hyaline and opaque zones, may be suitable for silver hake otoliths, but the degree of enhancement does not at present warrant the additional time required for preparation except in special studies. The use of metal ion stains may have some future advantage in detecting zones electronically.

The baking of otoliths at $285^{\circ} \mathrm{C}$ for about 5 minutes prior to sectioning has also been found to enhance the appearance of hyaline zones, but again the additional time required relative to the degree of improvement does not seem to be justified for routine age determination. 
Established conventions and definitions relating to the ageing of silver hake apply to whole otolith sections, and other ageing structures. These include such terms as birthdate, nucleus, hyaline zone, opaque zone, check or false annulus, pelagic zone, springsummer check, age group, year class, etc. By convention, silver hake originating from mid-summer spawning are classified as age 1 on 1 January when they are only 4-6 months old. This means that the actual age is at variance with the assigned age for the duration of survival.

Hyaline zones are translucent and appear dark over a black background with reflected light in both whole otoliths and sections, whereas opaque zones appear white on reflected light. The optical appearance of the zones is reversed when transmitted light is used. As for most species in temperate regions, hyaline zones are assumed to be laid down in periods of slow growth generally associated with winter conditions. The chemical structure of the growth-related zones accounts for the variation in optical density of the fast and slow growth periods (Blacker, 1974). Under ideal conditions, with well-defined annual periods of fast and slow growth, each year of growth should be represented by an opaque and a hyaline zone. Invariably, this situation does not occur in nature, as short periods of fast growth in winter or, more frequently, slow growth in summer may be reflected in the otolith by secondary opaque or hyaline zones. These zones are termed checks or false annuli and appear to occur at random in the otolith, although in some cases a characteristic check can be related to environmental stress affecting a large proportion of the population. Two such checks have been identified in silver hake and these are termed spring-summer check (SSC) and pelagic zone (PZ). The SSC is a hyaline zone frequently found between the first and second annuli and may be pronounced in some cases. This zone is thought to represent growth during late spring when age 1 fish move from juvenile concentrations to mix with the adult stock with a resultant change in diet and increased competition with larger fish. It may also represent a slowing down of growth during first spawning followed by a well-defined post-spawning opaque zone prior to the formation of the winter hyaline zone in the otolith. Age readers should anticipate the SSC zone, which can be identified by the relative radius of the first, SSC, second, third and subsequent hyaline zones.

A pelagic zone is characteristic of silver hake otoliths and is thought to form prior to the first winter hyaline zone at about 3-5 months of age. Juveniles are generally pelagic up to this age after which they migrate, under the influence of temperature and food availability, to the bottom where they tend to follow a demersal existence, and this change in habitat is assumed to be reflected in the otolith by the formation of a hyaline zone. The pelagic zone may range from being very small (coincident with the nucleus) to quite large (coincident with the first winter hyaline zone) and it cannot be distinguished as a separate zone in these extreme cases. However, in most cases, the pelagic zone is present as a well-defined hyaline zone which may be more pronounced than the subsequent winter hyaline zone. The size of the pelagic zone appears to vary in relation to geographic area with the tendency to decrease from north to south.

Hyaline zones, which are determined to represent winter growth, are counted as annuli, and 'age-group' is thus defined as the number of completed hyaline zones excluding the nucleus. Age-group 0 would be assigned to juveniles examined in the same year in which they were spawned. 'Year-class' is defined as the year of sampling minus the age-group (e.g. a fish as 3 years and caught in 1977 would be assigned to the 1974 year-class).

Time of formation of hyaline and opaque zones in the otoliths has not been documented other than to establish a general correlation of hyaline zones with winter growth and opaque zones with summer growth. As a general guide, hyaline zones are assumed to form during the period from late autumn (October) to late spring (May) and opaque zones from May to October. However, annual variation in growth as well as differences between juveniles and adults may result in anomolous otoliths which, for example, have no apparent hyaline zone at the edge in February. This situation may occur when environmental conditions are favorable to a portion of the population for an extended period, thus resulting in a prolonged 'summer growth' season. In the case of juveniles, which have a higher growth potential than adults, the effect of unfavorable environmental conditions on growth may be greater than is apparent in the otolith. The assignment of ages to this type of otolith frequently requires information on the appearance of the edge of the otolith, particularly for samples collected in January and February when a hyaline edge would be counted as an annulus. Conversely, otoliths with well-defined hyaline edges in the autumn must be carefully considered to ensure that the zone is not counted as an annulus. In general, the otoliths of silver hake from the Scotian Shelf tend to exhibit edge types consistent with the season, whereas those from fish taken farther south off the USA coast show greater variation in relation to season.

Geographic variation in the relative dimensions of the pelagic, first and second hyaline zones and in the edge type has been identified as a contributing factor 
in differing estimates of age. Although some characteristics of zones with respect to area have been noted, both intra-area and annual variation continues to limit specific classification. Comments on the pelagic zone and edge type in this regard have been noted above. The size of the first annulus or hyaline zone appears to be related to area and is influenced by spawning time and environmental conditions. In general, this zone is distinct from the pelagic zone and is quite large in otoliths of fish caught on the Scotian Shelf, whereas it tends to be small and similar to the pelagic zone in fish caught on Georges Bank and farther south. The second annulus is characteristically large and distinct in most of the otoliths regardless of area, and it is frequently used as a reference to identify other annuli. Hyaline zones outside of the second one are generally distinct and the increments appear to be uniform. Also, checks are encountered less frequently in the outer zones, but some split zones have been noted.

Variation in the appearance of zones in different parts of the otolith surface have been identified as a possible source of different estimates of age. The entire surface of the otolith should be observed, but tendency for split zones to occur in the anterior (pointed) end indicates that greater consideration should be given to the appearance of the zones in the posterior (rounded) part of the otolith when counting the annuli. A similar situation in otolith sections implies that preferred use of the ventral (rounded) aspect.

As indicated above, variation in the relative dimensions of the pelagic zone, the first annulus and the spring-summer check both within and between areas creates problems in estimating the age and growth of juveniles. Various combinations of these zones are given in Table 1, classified as small, average, large, absent or coincident with another zone. Possible interpretation of the various types is indicated and these are assessed as indicated in the column headed 'key'. Although all of the types are possible, some occur more frequently than others within geographic areas, and these are indicated in the last column of Table 1. Relative dimensions of the various zones based on otolith measurement data of Hunt and Stuart (MS 1978) for silver hake on the Scotian Shelf are given in Table 2, but the values for the pelagic zone (PZ) are probably over-estimated due to masking of the central zones in whole otoliths and the high standard deviations of the spring-summer check (SSC) measurements suggest some incorrect classifications.

Exchange of otoliths between expert age readers is a continuing aspect of the program involving age determination in silver hake. Each sample should consist of a set of glycerin-stored whole otoliths and a
TABLE 1. Variation in the size of otolith zones with possible interpretation for various geographic areas.

\begin{tabular}{|c|c|c|c|c|c|c|c|}
\hline \multicolumn{3}{|c|}{ Otolith zone and size } & \multicolumn{4}{|c|}{ Interpretation } & \multirow{2}{*}{$\begin{array}{c}\text { Geographic } \\
\text { area }^{c}\end{array}$} \\
\hline$P Z$ & 1 & SSC & $\mathrm{PZ}$ & 1 & SSC & Key $^{6}$ & \\
\hline \multirow[t]{12}{*}{$S^{3}$} & $S^{a}$ & $S^{a}$ & $\mathrm{PZ}$ & 1 & SSC & 1 & $z$ \\
\hline & & $M$ & $P Z$ & 1 & SSC & 1 & $\mathbf{z}$ \\
\hline & & $\mathrm{L}$ & $P Z$ & 1 & 2 & 3 & $Z$ \\
\hline & & $A$ & 1 & ssc & - & 2 & $z$ \\
\hline & $M$ & s & $P Z$ & 1 & SSC & 1 & $z$ \\
\hline & & $M$ & $P Z$ & 1 & SSC & 1 & z \\
\hline & & $\mathbf{L}$ & $\mathrm{PZ}$ & 1 & 2 & 3 & $z$ \\
\hline & & A & 1 & 2 & - & 3 & z \\
\hline & $\mathbf{L}$ & $\mathrm{s}$ & $P Z$ & 1 & ssc & 1 & Y \\
\hline & & $M$ & $P Z$ & 1 & SSC & 1 & $Y$ \\
\hline & & $L$ & 1 & 2 & 3 & 3 & $x$ \\
\hline & & $A$ & 1 & ssc & - & 3 & $X, Y$ \\
\hline \multirow[t]{12}{*}{$M$} & $S$ & $\mathrm{~S}$ & $\mathrm{PZ}$ & 1 & SSC & 1 & $Y, Z$ \\
\hline & & $M$ & $\mathrm{PZ}$ & 1 & SSC & 1 & $Y, Z$ \\
\hline & & $\mathrm{L}$ & $\mathbf{P Z}$ & 1 & 2 & 3 & $z$ \\
\hline & & A & 1 & SSC & - & 2 & $Y$ \\
\hline & $M$ & s & $P Z$ & 1 & ssc & 1 & $X, Y, Z$ \\
\hline & & $M$ & $P Z$ & 1 & SSC & 1 & $X, Y, Z$ \\
\hline & & $\mathbf{L}$ & $P Z$ & 1 & 2 & 3 & $X, Y, Z$ \\
\hline & & A & 1 & SSC & - & 2 & $X, Y, Z$ \\
\hline & $L$ & $S$ & $P Z$ & 1 & SSC & 1 & $X, Y$ \\
\hline & & $M$ & $P Z$ & 1 & SSC & 1 & $X, Y$ \\
\hline & & $\mathrm{L}$ & $P Z$ & 1 & 2 & 3 & $X, Y$ \\
\hline & & A & 1 & 2 & - & 3 & $X, Y$ \\
\hline \multirow[t]{12}{*}{ L } & $S$ & $s$ & 1 & SSC & 2 & 3 & $z$ \\
\hline & & $M$ & 1 & SSC & 2 & 3 & $X, Y$ \\
\hline & & L & 1 & SSC & 2 & 3 & $x, z$ \\
\hline & & A & 1 & SSC & - & 2 & $X, Y$ \\
\hline & $M$ & $S$ & $P Z$ & 1 & SSC & 1 & $X, Y$ \\
\hline & & $M$ & $P Z$ & 1 & SSC & 1 & $X, Y$ \\
\hline & & $L$ & 1 & SSC & 2 & 3 & $X, Y$ \\
\hline & & A & 1 & 2 & - & 3 & $X, Y$ \\
\hline & $L$ & $S$ & $P Z$ & 1 & SSC & 1 & $X, Y$ \\
\hline & & $M$ & $P Z$ & 1 & SSC & 1 & $X, Y$ \\
\hline & & $\mathrm{L}$ & 1 & 2 & 3 & 3 & $X, Y$ \\
\hline & & A & 1 & 2 & - & 3 & $X, Y$ \\
\hline \multirow[t]{12}{*}{ A } & $\mathrm{s}$ & $S$ & - & $P Z$ & 1 & 2 & $z$ \\
\hline & & $M$ & - & $\mathrm{PZ}$ & 1 & 2 & z \\
\hline & & $L$ & - & $\mathrm{PZ}$ & 1 & 2 & $x, Z$ \\
\hline & & A & - & $P Z$ & - & 3 & $z$ \\
\hline & $M$ & $S$ & - & $P Z$ & 1 & 2 & z \\
\hline & & $M$ & - & 1 & SSC & 1 & z \\
\hline & & $L$ & - & 1 & 2 & 3 & $z$ \\
\hline & & A & - & $P Z$ & - & 3 & $z$ \\
\hline & $\mathbf{L}$ & $s$ & - & $P Z$ & 1 & 2 & $Y, Z$ \\
\hline & & $M$ & - & 1 & SSC & 1 & $Y$ \\
\hline & & $\mathrm{L}$ & - & 1 & 2 & 3 & $x$ \\
\hline & & $A$ & - & 1 & - & 1 & $Y$ \\
\hline
\end{tabular}

\footnotetext{
a $S=$ small, $M=$ average,$L=$ large $A=$ absent or coincident with an adjacent zone.

b 1 = correct age and interpretation, 2 = correct age but incorrect interpretation, $3=$ incorrect age and interpretation.

c $\mathrm{X}=$ Scotian Shelf, $\mathrm{Y}=$ Gulf of Maine. $\mathrm{Z}=$ Georges Bank.
} 
TABLE 2. Relative dimensions of otolith zones in silver hake otoliths from the Scotian Sheif

\begin{tabular}{cccccc}
\hline & \multicolumn{2}{c}{ Mean $(\mathrm{mm})$} & & \multicolumn{2}{c}{ Standard deviation } \\
\cline { 2 - 3 } \cline { 5 - 6 } Zone & Radius & Diameter & & Radius & Diameter \\
\hline Pelagic & 2.2 & 4.2 & & 1.67 & 2.92 \\
1 & 3.3 & 7.1 & & 1.47 & 2.39 \\
SSC & 4.8 & 11.2 & & 3.04 & 6.52 \\
2 & 5.0 & 11.7 & & 1.38 & 2.16 \\
3 & 6.0 & 14.2 & & 1.35 & 2.08 \\
4 & 6.7 & 16.1 & & 1.42 & 2.26 \\
\hline
\end{tabular}

set of sections (or polished half otoliths), and all relevant data on the sample, including fish length and sex, should be provided, together with a set of otolith photographs, if possible. To facilitate discussion of interpretations, codes suggested by Jensen (1965) and modified (ICNAF MS 1977) should be used as follows:

a) Hyaline zones (winter growth)

$\mathrm{VNH}$ - very narrow hyaline, winter growth just visible on edge

$\mathrm{NH}$ - narrow hyaline, winter growth starting

$H$ - hyaline, winter zone well formed

WH - wide hyaline, winter zone almost complete.

b) Opaque zones (summer growth)

VNO - very narrow opaque, summer growth just visible on edge

NO - narrow opaque, summer growth starting

O - opaque, summer zone well formed

WO - wide opaque, summer zone almost complete

c) Classification of hyaline zones

$P Z$ - pelagic zone

SPL - split zone

C - check or false annulus

SSC - spring-summer check

$\underline{X X}$ - strong or clear zone (underline)

$\overline{X X}$ - weak or diffuse zone (overline)

d) Recording of ages

$6(5)$ - preferred age 6 , possible 5

2 ? - indicated age inconsistent with other data (e.g. length)

A typical code for an age 4 fish might be as follows: $\overline{\mathrm{PZ}}, 1$, SSC, 2, SPL3, 4, NO. Photographs of 30 silver hake otoliths are shown in the Appendix together with a possible interpretation for each.

\section{Age Validation}

Establishing the true age of a fish can be accomplished by both direct and indirect methods.
Direct methods include multiple ageing of the same structure, comparison of ages from different structures, and growth-related studies such as tagging. Indirect methods include the analysis of length frequency distributions and the comparision of year-class data over a number of years in terms of consistency of age composition.

Multiple ageing of otoliths by the same reader or by different readers does not necessarily indicate the true age of the fish but rather ensures consistency of interpretation. Discussion or justification of the estimate of age makes it necessary to relate the interpretation to the probable life history of the species, and any inconsistencies usually become apparent. Comparison of different structures is based on the premise that changes in growth should be reflected in all indicators, and a zone which is apparent in otoliths but not in scales, vertebrae, etc., must be explained on the basis of growth or other physiological factors or be discounted as an annulus. Comparative studies on ageing from otoliths, scales and vertebrae are presently being conducted.

Tagging of fish and their subsequent recapture can yield information on age by establishing a minimum possible age which can be related to otolith zones. If the interval between release and recapture is sufficiently long and if length measurements were recorded upon release and recapture, the growth increment can be related to the time interval. The relationship between fish length and otolith (or scale) size can then be used to outline the growth of the otolith over the time interval and the zone characteristics related to the annuli. Similar results can be obtained by injecting the fish with a chemical, such as tetracycline, which results in a visible mark being laid down in the otolith at the time of release of the tagged fish. Tagging of silver hake has not been attempted but such experiments could provide valuable data on stock boundaries and growth-related problems. Some unique characteristics in otolith morphology, specific to a year-class, can frequently be used as a biological tag to identify the age-group in subsequent years.

Indirect methods of age validation do not involve comparing the ages of individual fish but rather the relating of age frequencies with other data for evidence of consistency. One method is to assess the probability of incorrect ageing by following the relative abundance of a year-class from age composition data for a number of years. Using a technique such as cohort analysis, in which catch-at-age is related to fishing mortality yielding estimates of population numbers by age-group, unrealistic changes in population structure or mortality rate may be traced to incorrect ageing. However, only gross changes will be 
apparent, as the method is restricted by the requirement for accurate estimates of fishing mortality and other input parameters.

Analysis of length frequencies for evidence of normally-distributed components representing yearclasses may be useful, provided that the distribution of lengths within a year-class is normal and that the degree of overlap between adjacent age-groups is small. Silver hake grow rapidly as juveniles and appear to be well suited to frequency distribution analysis. Several methods are available for isolating the components of length frequency distributions and most require the transformation of the frequency to natural logarithms and the fitting of parabolas by a method of least squares to the apparent modes. This technique requires a logarithmic transformation, because the transformed equation of a normal distribution is reduced to a parabola of the form

where

$$
\begin{aligned}
\ln (\mathrm{Y}) & =\mathrm{A}+\mathrm{BX}+\mathrm{CX}^{2} \\
\mu & =-\mathrm{B} / 2 \mathrm{C} \\
\sigma & =-1 / 2 \mathrm{C} \\
\mathrm{k} & =-\frac{\pi}{\mathrm{C}} \cdot \mathrm{e}\left(\mathrm{A}-\mathrm{B}^{2} / 4 \mathrm{C}\right)
\end{aligned}
$$

the parameters $\mu, \sigma$ and $\mathrm{k}$ being the mean, standard deviation, and proportion of the catch frequency.

The method requires visual inspection of the transformed frequency distribution to select lower and upper intervals of length to which the parabola is fitted. Since younger age-groups tend to be more discrete, modes are resolved from left to right and the residual frequency, remaining after the contribution of each calculated modal group is removed, is examined for additional age-groups. An example of the method, using known values, is shown in Fig. 3 , and the results indicate a good degree of accuracy. The derived values of the mean, standard deviation and proportion for catch frequencies can be compared with values derived from the application of age-length keys for evaluation concerning the possibility of incorrect ageing if significant differences are indicated.

In summary, age determination in silver hake, based on interpretation of otoliths and other criteria, is subject to several conventions or definitions of anticipated otolith types. Geographic variation in the appearance of growth zones in otoliths present problems which limit generalization concerning the estimation of age. However, this variation appears to be largely confined to growth of juvenile, as growth of adults (greater than age 2) is reflected in the otolith by relatively clear and uniform increments in which the usual checks can be readily identified as such. Further

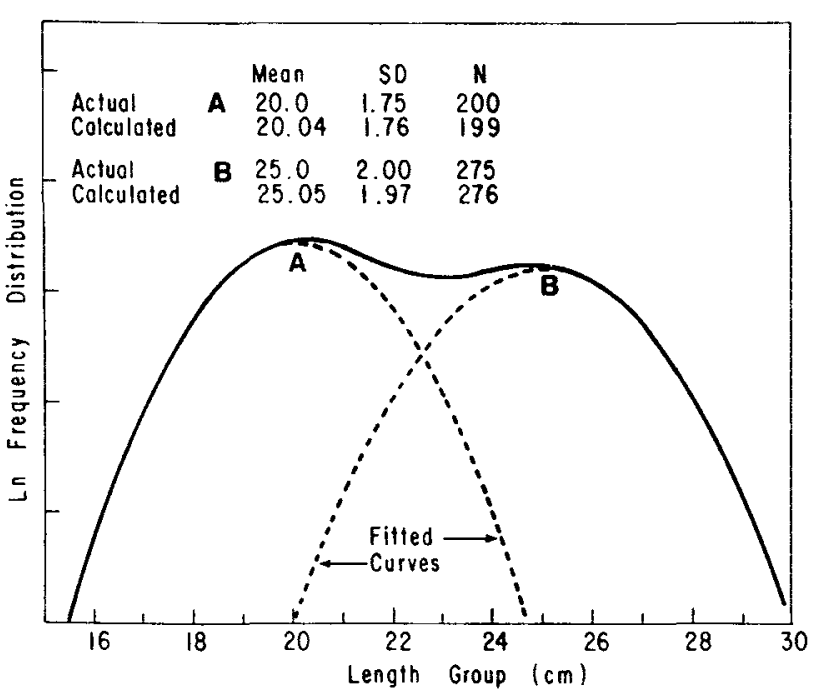

Fig. 3. Modal analysis of a length frequency for two over-lapping age-groups, using a logarithmic transformation.

clarification of otolith types and growth in juveniles awaits additional studies on stock separation, variation in year-class growth, spawning variation, etc.

\section{Growth}

Attempts to describe growth of silver hake are obviously influenced by interpretation of otoliths or other structures used for estimating age. In view of the present uncertainty about size at age in juveniles, the accuracy and validity of growth curves based on such data are limited to general conclusions within specific geographic areas.

Two recent studies of length-at-age data have provided estimates of growth for the stock on the Scotian Shelf. Hunt (1978) examined length frequencies from research vessel surveys by a technique of modal analysis. Estimated modal lengths were plotted on a time scale and the points joined to give a series of growth curves based on the von Bertalanffy model. The resultant averaged growth curves (Fig. 4) were significantly different for males and females larger than $24 \mathrm{~cm}$ in length. The calculated asymptotic length for males $(35.08 \mathrm{~cm})$ agrees with observed maximum lengths in the fishery, but the value for females $(43.87 \mathrm{~cm})$ is lower than the observed maximum length $(>60 \mathrm{~cm})$, although fish greater than $40 \mathrm{~cm}$ presently constitute a very small proportion of the population. Hunt and Stuart (MS 1978) measured the relative dimension of otoliths and were able to back-calculate length-at-age. They found a good correlation between otolith size and fish length (Fig. 5), and the growth curves based on these calculations were similar to those of Fig. 4, thus tending to validate growth rates for silver hake on the Scotian Shelf. 


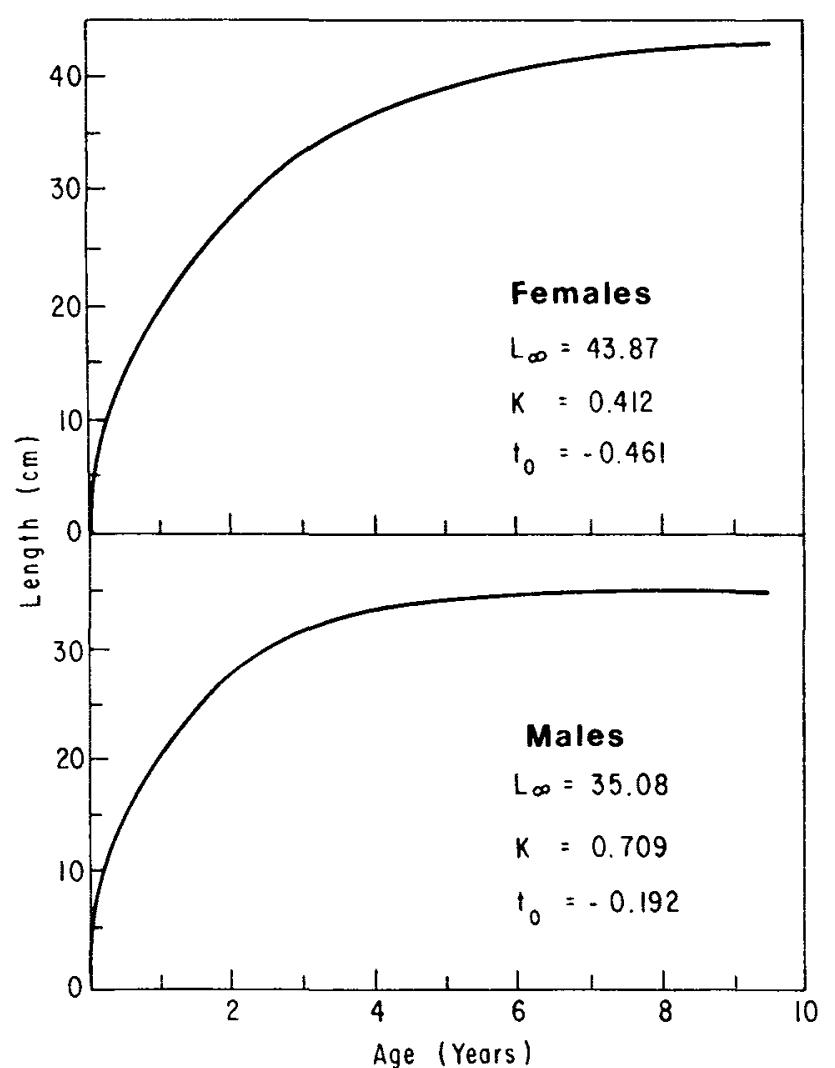

Fig. 4. Von Bertalanffy growth curves by sex for silver hake on the Scotian Shelf, using length-at-age values from modal analysis and otolith ageing.

Data on growth of silver hake larvae are presently limited to results from occasional research vessel cruises which have provided length frequencies and distribution patterns. In order to relate such results to spawning duration and to apparent growth in the spawning and post-spawning periods, it is necessary to have a relatively continuous series of observations or data from a series of successive surveys in relatively short time intervals.

The results from a joint USSR-Canada plankton survey (Noskov et al., MS 1978) indicate that spawning occurs progressively later from west to east on the Scotian Shelf. They found silver hake eggs and larvae 2-21 mm long (average $6.43 \mathrm{~mm}$ ) on Sable Island Bank in late September. Larvae taken farther eastward averaged $5.40 \mathrm{~mm}$ and those to the west of Browns Bank averaged $10.14 \mathrm{~mm}$. However, the total number of larvae taken was small $(1,135)$, which indicates that the timing of the cruise may have been after the period of peak concentrations and that growth and dispersion of the earlier-hatched larvae made them less susceptible to capture by the sampling gear.

Significant numbers of silver hake larvae were taken during a Canadian survey of the Scotian Shelf in

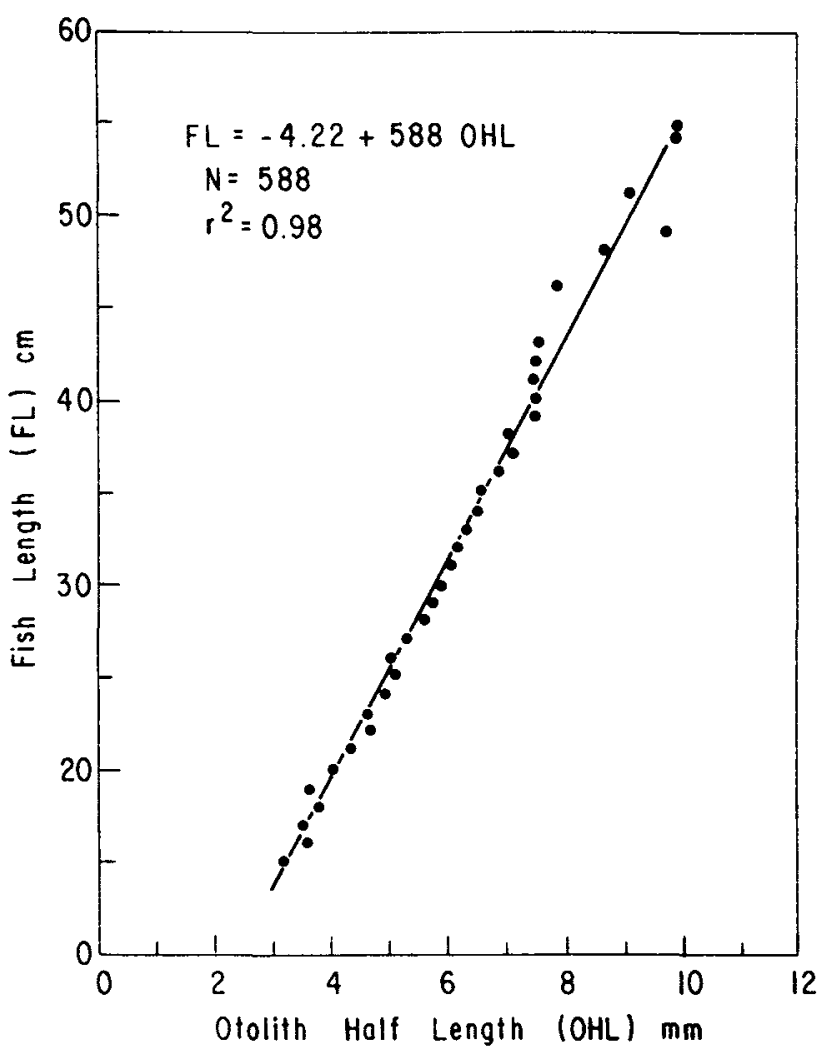

Fig. 5. Relationship between fish length and otolith half-length for silver hake on the Scotian Shelf.

mid-August 1976. The largest catches were in the Browns Bank and Sable Island Bank areas (Fig. 6) with average lengths of $7.19 \mathrm{~mm}$ and $5.38 \mathrm{~mm}$ based on measurements of 1,944 and 13,999 larvae respectively. Modal analyses of the length frequencies indicate modes at 6.59, 10.46 and $12.02 \mathrm{~mm}$ for Browns Bank and $4.81,8.00$ and $12.17 \mathrm{~mm}$ for Sable Island Bank. These results are consistent with those reported by Noskov et al. (MS 1978) which show that spawning

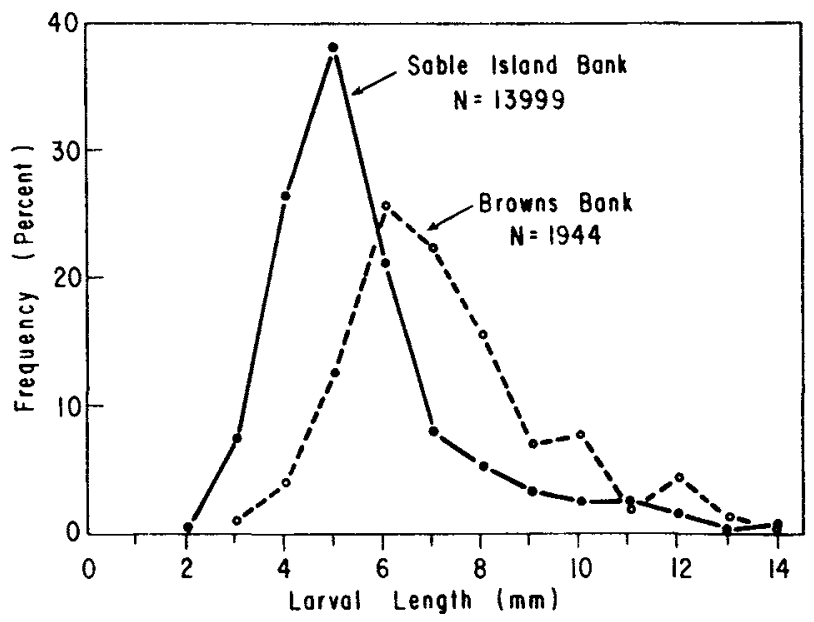

Fig. 6. Length distributions of silver hake larvae on the Scotian Shelf in August 1976. 
occurs progressively later from west to east on the Scotian Shelf. The presence of silver hake eggs on Sable Island Bank in late September (Noskovet al., MS 1978) and of large numbers of larvae in mid-August indicates that spawning occurs at least from July to mid-September or later. Such a range in spawning duration undoubtedly has a significant effect on the size of juveniles at age, particularly if early growth is rapid.

\section{Summary}

Age determination of silver hake based on interpretation of otoliths has been discussed by international researchers in recent years, and general agreement has been reached on several unique characteristics of the otolith. The most significant of these are the presence of a 'pelagic' hyaline zone before the first annulus and a strong hyaline check between the first and second annuli. Geographic differences in peak spawning times and in the duration of spawning are also thought to have a significant effect on the relative size of the first annulus. Variation in the size and intensity of these zones appears to be specific within areas, and it is essential that age readers be familiar with these regional differences to ensure correct estimation of age.

Growth of silver hake appears to be adequately described by von Bertalanffy type curves, which show very rapid growth in juveniles with divergence for males and females greater than $25 \mathrm{~cm}$ in length. Observed maximum lengths for males and females are approximately 37 and $65 \mathrm{~cm}$ respectively, and the maximum age appears to be about 12 years. Indirect methods of ageing, such as length frequency modal analysis and back-calculation of length-at-age from otolith measurements, appear to be possible for this species, the calculated mean length-at-age values for both methods showing reasonably good agreement.

Ageing workshops and discussions among age readers have identified the first annulus as the most difficult to determine, and most of the disagreement in ageing of silver hake can be attributed to variation in interpretation of early growth. Therefore, additional information on regional variation in spawning is required to establish the potential growing season in the first year and thus provide more confidence in the estimation of the size of the first annulus. A continuing exchange of otoliths between age readers is suggested as a means of maintaining consistency in ageing based on guidelines for otolith interpretation.

Subject to the limitations noted, it is anticipated that agreement between age readers of silver hake otoliths can be maintained at or above $75 \%$, and that the level of agreement can be further improved through future research on growth of juveniles.

\section{References}

ANDERSON, E. D., and F.E. NICHY. MS 1975. A comparison of US and USSR silver hake ageing. ICNAF Res. Doc., No. 13, Serial No. 3457 .

BLACKER, R. W. 1974. Recent advances in otolith studies. In: Sea Fisheries Research, F. R. Harden Jones (ed.). Paul Elek (Sci. Books) Ltd., London, p. 67-90.

DOUBLEDAY, W. G. and J. J. HUNT. MS 1976. A revised assessment of the $4 \mathrm{VWX}$ silver hake fishery, incorporating preliminary 1976 data. ICNAF Res. Doc., No. 160, Serial No. 4056.

HUNT, J. J. 1978. Age, growth and distribution of silver hake, Merluccius bilinearis, on the Scotian Shelf. ICNAF Sel. Papers, No. 3: 33-44.

1979. Back-calculation of length-at-age from otoliths for silver hake on the Scotian Shelf. ICNAF Sel. Papers, No. 5: 11-17.

HUNT, J. J. and P. J. STUART. MS 1978. Back-calculation of silver hake length at age from otoliths. ICNAF Res. Doc., No. 42, Serial No. 5204.

ICNAF. MS 1976. Report of silver hake ageing workshop, Dartmouth, Canada, 1-3 April 1976 (J. J. Hunt, Convener). ICNAF Sum. Doc., No. 21, Serial No. 3850.

MS 1977. Report of silver hake ageing workshop, St. Andrews, Canada, 14-18 March 1977 (J. J. Hunt, Convener). Ibid, No. 13, Serial No. 5073.

MS 1978. Report of silver hake ageing workshop, Dartmouth, Nova Scotia, Canada, March 1978 (J. J. Hunt, Convener). Ibid, No. 10, Serial No. 5211.

JENSEN, A. C. 1965. A standard terminology and notation for otolith readers. ICNAF Res. Bull., No. 2: 5-7.

LEIM, A. H., and W. B. SCOTT. 1966. Fishes of the Atlantic coast of Canada. Bull. Fish. Res. Bd. Canada, No. 155, 485 p.

MOMBECK, F. 1971. Notes on the distinction of Northwest Atiantic hakes, Merluccius albidus and M. bilinearis. ICNAF Res. Bull., No. 8: 87-89.

NOSKOV, A. S. MS 1976. Estimation of stock size and allowable catch of silver hake on the Nova Scotia Shelf in ICNAF Division $4 \mathrm{~W}$. ICNAF Res. DOC., No. 57, Serial No. 3843.

NOSKOV, A. S., V. P. KARAULOVSKY, A. N. ROMANCHENKO, and A. I. SHERSTIUKOV. MS 1978. Distribution and abundance of silver hake eggs and larvae and environmental conditions off Nova Scotia in September-October 1977. ICNAF Res. Doc., No. 32, Serial No. 5193

SARNITS, A. A., and V.I. SAUSKIN. 1967. Hydrological conditions and distribution of silver hake Merluccius bilinearis Mitchell, on Georges Bank and off Nova Scotia in 1962-64. ICNAF Res. Bull., No. 4: 76-86.

SCOTT, J. S. MS 1976. Summer distribution of groundfish on the Scotian Shelf, 1970-74. Fish. Mar. Serv. Canada, Tech. Rept., No. $635,51 \mathrm{p}$. 


\section{APPENDIX}

\section{Photographs of Typical Otoliths}

Various characteristic types of silver hake otoliths are illustrated on the following pages. Whole glycerin-stored otoliths were selected and all photographs were taken at the same magnification using a Nikon $\mathrm{F}$ camera with $85 \mathrm{~mm}$ bellows extension and $55 \mathrm{~mm}$ Micro Nikkor lens in normal position. The light source consisted of two American Optical microscope lamps set about $12 \mathrm{~cm}$ from the subject and inclined at an angle of 45 degrees. Incident light was blue filtered and light passing through the camera lens was filtered with a No. 29 (dark red) Tiffon filter. Exposure was 1 second at F11 using Kodak Panatomic $X$ film. Interpretation of each otolith is indicated in the following table using the coding system suggested in the 'Age Determination' section of the paper.

\begin{tabular}{|c|c|c|c|c|c|}
\hline $\begin{array}{l}\text { Otolith } \\
\text { number }\end{array}$ & $\begin{array}{c}\text { Month of } \\
\text { capture }\end{array}$ & $\begin{array}{l}\text { Fish } \\
\text { length } \\
(\mathrm{cm})\end{array}$ & Sex & $\begin{array}{c}\text { Maturity } \\
\text { stage }\end{array}$ & Interpretation \\
\hline 1 & Mar & 11 & $?$ & 1 & $P Z 1 C$ \\
\hline 2 & Jul & 21 & $\mathrm{~F}$ & 1 & $P Z 1 C$ \\
\hline 3 & Jul & 20 & $M$ & 1 & $P Z \bar{C} 1$ \\
\hline 4 & Mar & 23 & $\mathrm{~F}$ & 1 & $\overline{P Z} \div \mathrm{C}$ \\
\hline 5 & Jul & 26 & $M$ & if & $\mathrm{PZ} \overline{1} \mathrm{C} 2$ \\
\hline 6 & Jul & 22 & $M$ & 1 & $P Z T_{2}$ \\
\hline 7 & Mar & 25 & $M$ & 1 & $P Z 1 C \overline{2}$ \\
\hline 8 & Mar & 23 & $F$ & 1 & $P Z \underline{1} 2 \underline{C}$ \\
\hline 9 & Jul & 27 & $\mathrm{~F}$ & VIII & $\mathrm{PZ} \mathrm{1}_{\mathrm{C}} \mathrm{2}^{\overline{3}}$ \\
\hline 10 & Jul & 27 & $M$ & III & $\underline{P Z} 1 \mathrm{C} \underline{\overline{2}}$ \\
\hline 11 & Jul & 25 & $M$ & 11 & $\mathrm{PZ} \backslash \mathrm{C}$ SPL2 \\
\hline 12 & Jul & 29 & $\mathrm{~F}$ & $\|$ & $\mathrm{PZ} 1 \mathrm{C} 2$ \\
\hline 13 & Jul & 32 & $F$ & II & $\overline{\mathrm{PZ}} \underline{1} \mathrm{C} \underline{2}$ \\
\hline 14 & Mar & 32 & $M$ & VIII & $P Z 123$ \\
\hline 15 & Jul & 29 & $\mathrm{~F}$ & III & $\mathrm{PZ} 1 \mathrm{C} 2$ \\
\hline 16 & Jul & 33 & $\mathrm{~F}$ & III & $P Z 1 C_{2}$ \\
\hline 17 & Jul & 33 & $\mathrm{~F}$ & 11 & $\overrightarrow{P Z} \overline{1} C_{2}$ \\
\hline 18 & Jul & 31 & $\mathrm{~F}$ & II & $\mathrm{PZ} 1 \mathrm{Cl}_{2}$ \\
\hline 19 & Jul & 32 & $\mathrm{~F}$ & II & $\underline{P Z} S P L 1 C \underline{2}$ \\
\hline 20 & Jul & 31 & $\mathrm{~F}$ & III & $\underline{\mathrm{PZ}} 1 \mathrm{C}_{2}$ \\
\hline 21 & Mar & 30 & $\mathrm{~F}$ & VII & $\mathrm{PZ} 1 \mathrm{C} 2 \underline{3}$ SPL 4 \\
\hline 22 & Jul & 35 & $M$ & $\|$ & $P Z 1 C 2345$ \\
\hline 23 & Jul & 36 & $F$ & 11 & $P Z 1234$ SPL5 6 \\
\hline 24 & Jul & 35 & $F$ & II & PZ1234 SPL5 \\
\hline 25 & Jul & 37 & $\mathrm{~F}$ & II & $P Z \overline{\overline{1}}$ SPL2 SPL3 4 \\
\hline 26 & Jul & 42 & $\mathrm{~F}$ & II & $\mathrm{PZ} 12 \underline{3} \mathrm{C} 4$ \\
\hline 27 & Jul & 42 & $\mathrm{~F}$ & VII & $P Z 1 C 2345678$ \\
\hline 28 & Jul & 42 & $\mathrm{~F}$ & III & $\mathrm{PZ} \overline{1} \mathrm{C} 2 \mathrm{CSPL3} 45$ \\
\hline 29 & Ju: & 44 & $\mathrm{~F}$ & III & $P Z C 12$ SPL3 4 \\
\hline 30 & Jul & 50 & $\mathrm{~F}$ & IV & $\mathrm{PZ} 1 \overline{2} 34 \overline{5} \frac{1}{6}$ \\
\hline
\end{tabular}



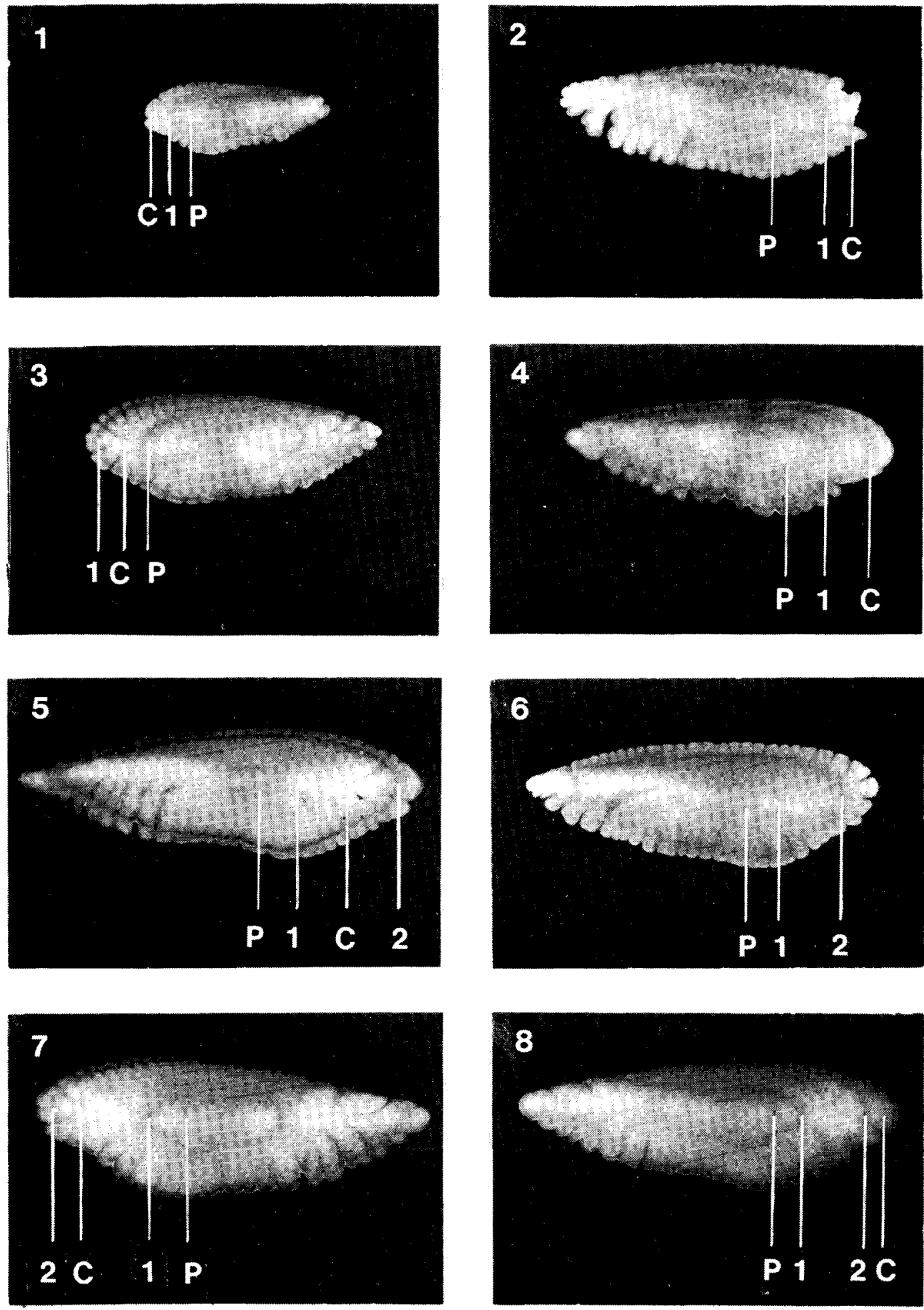

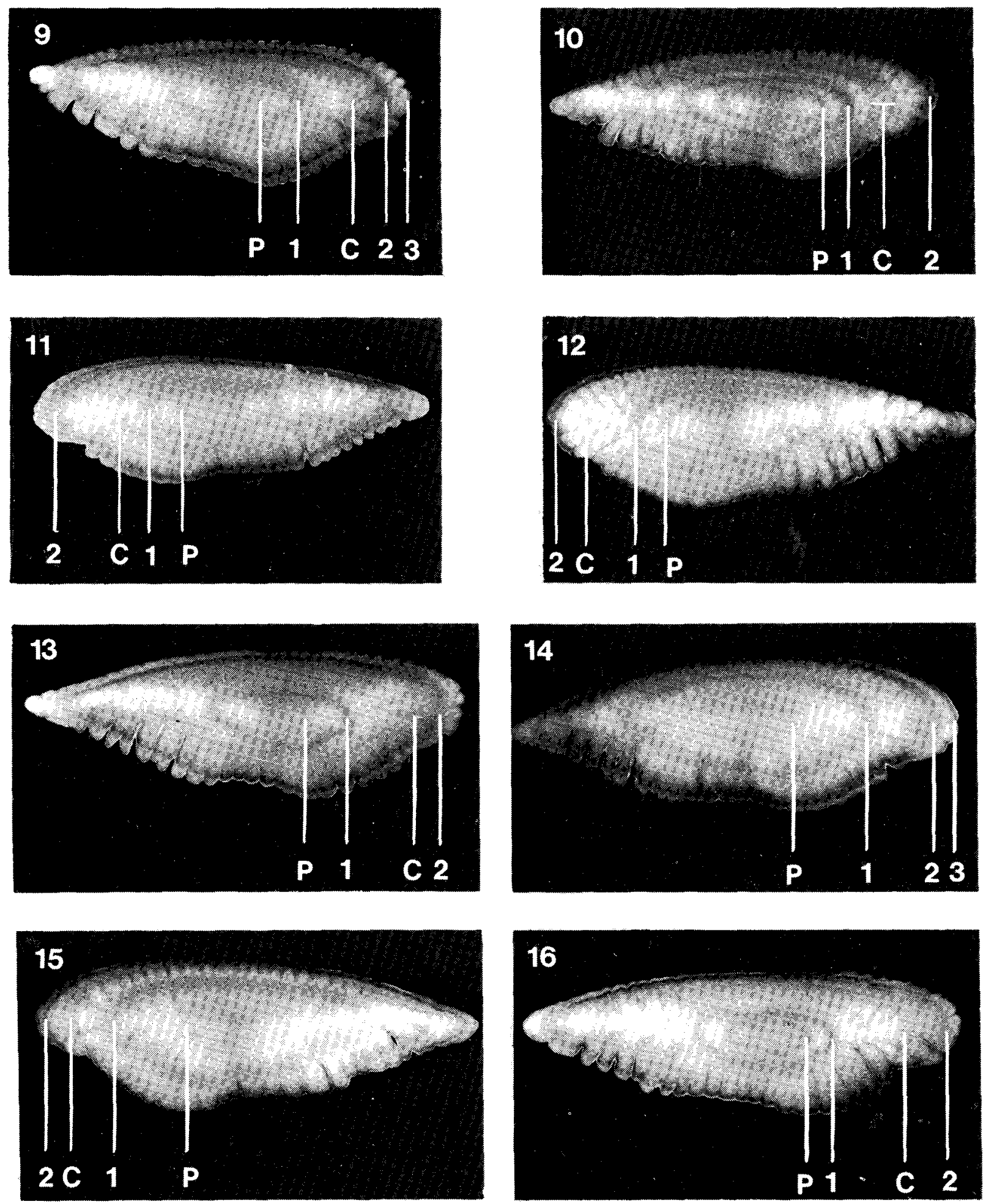

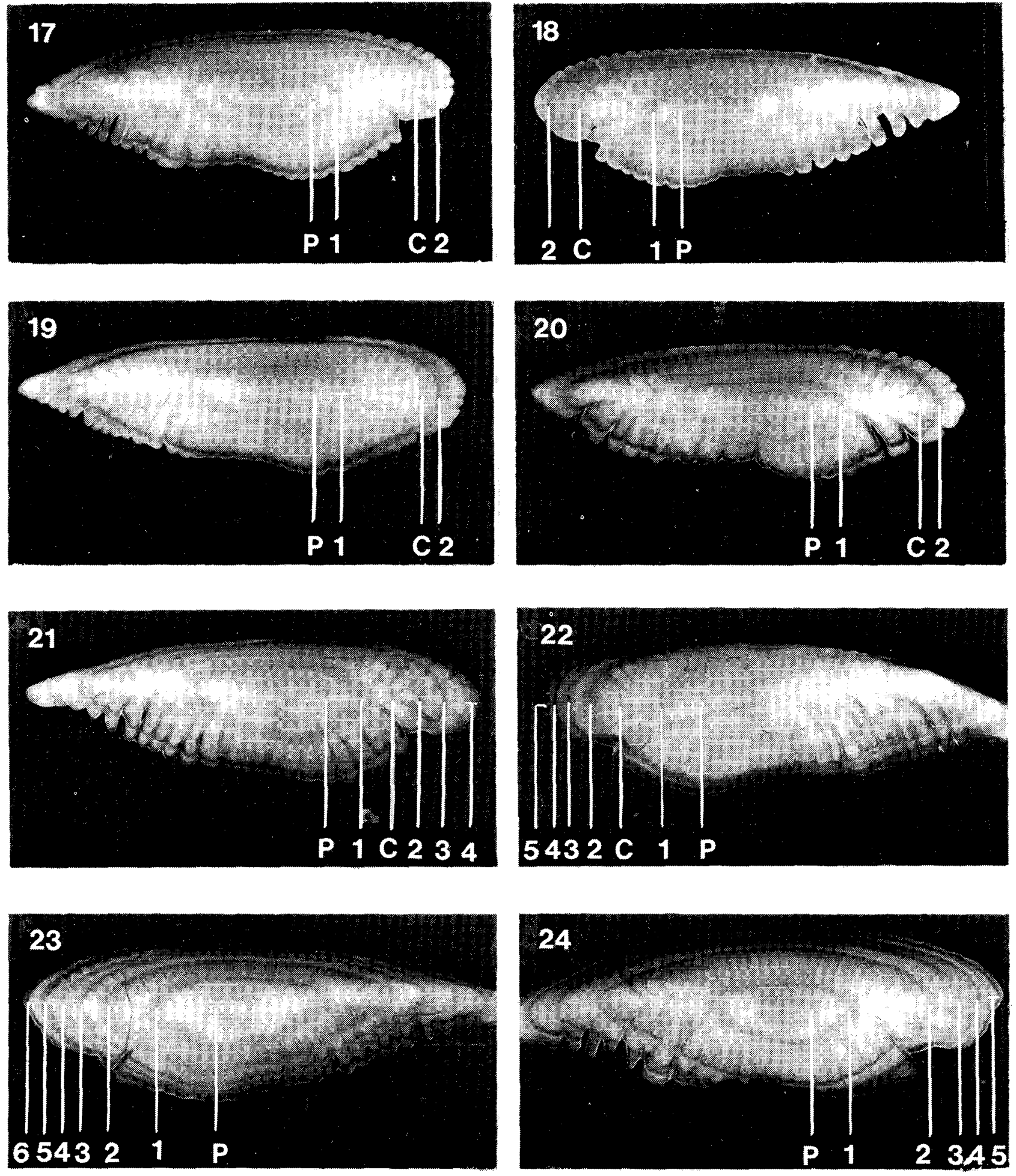

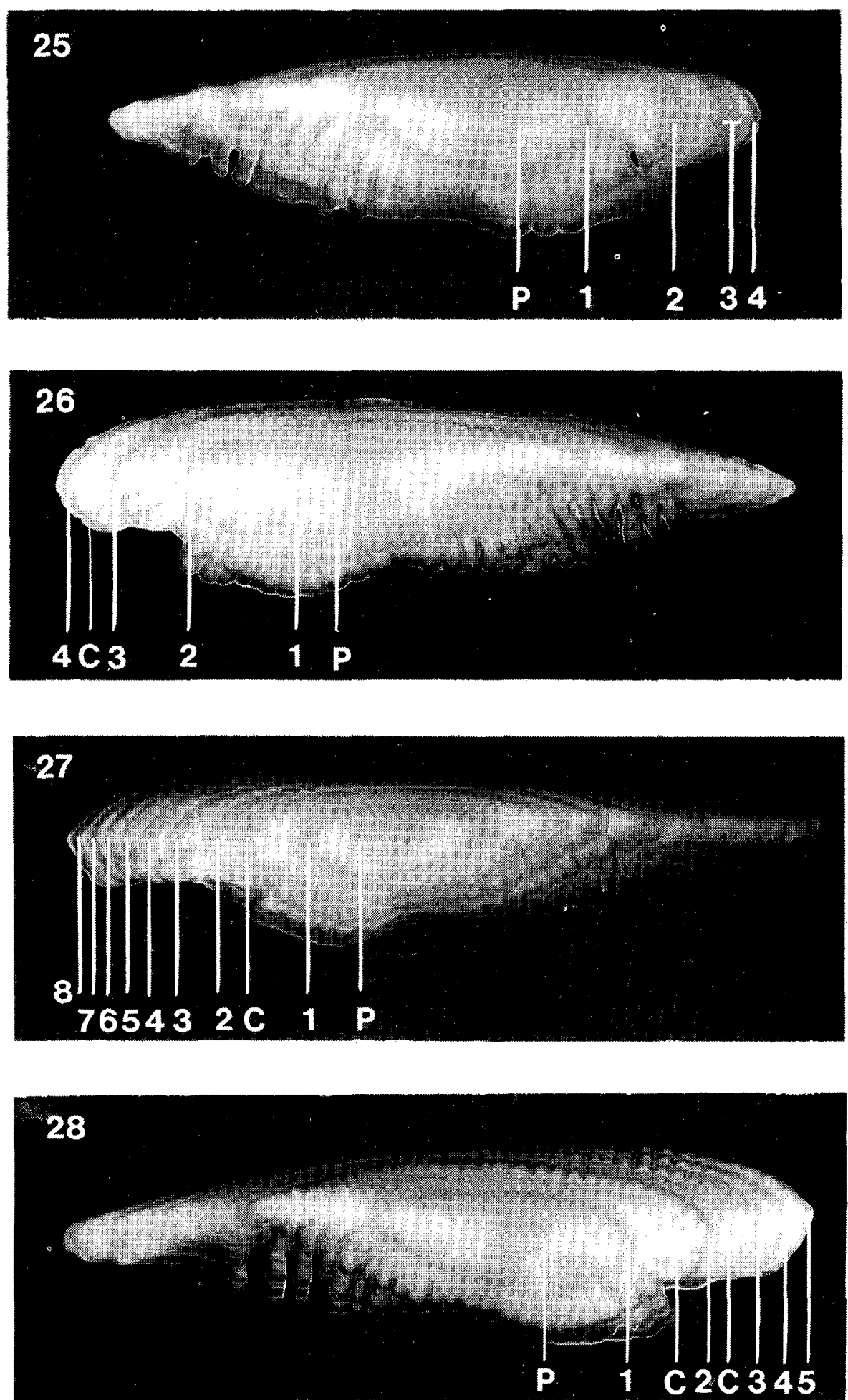

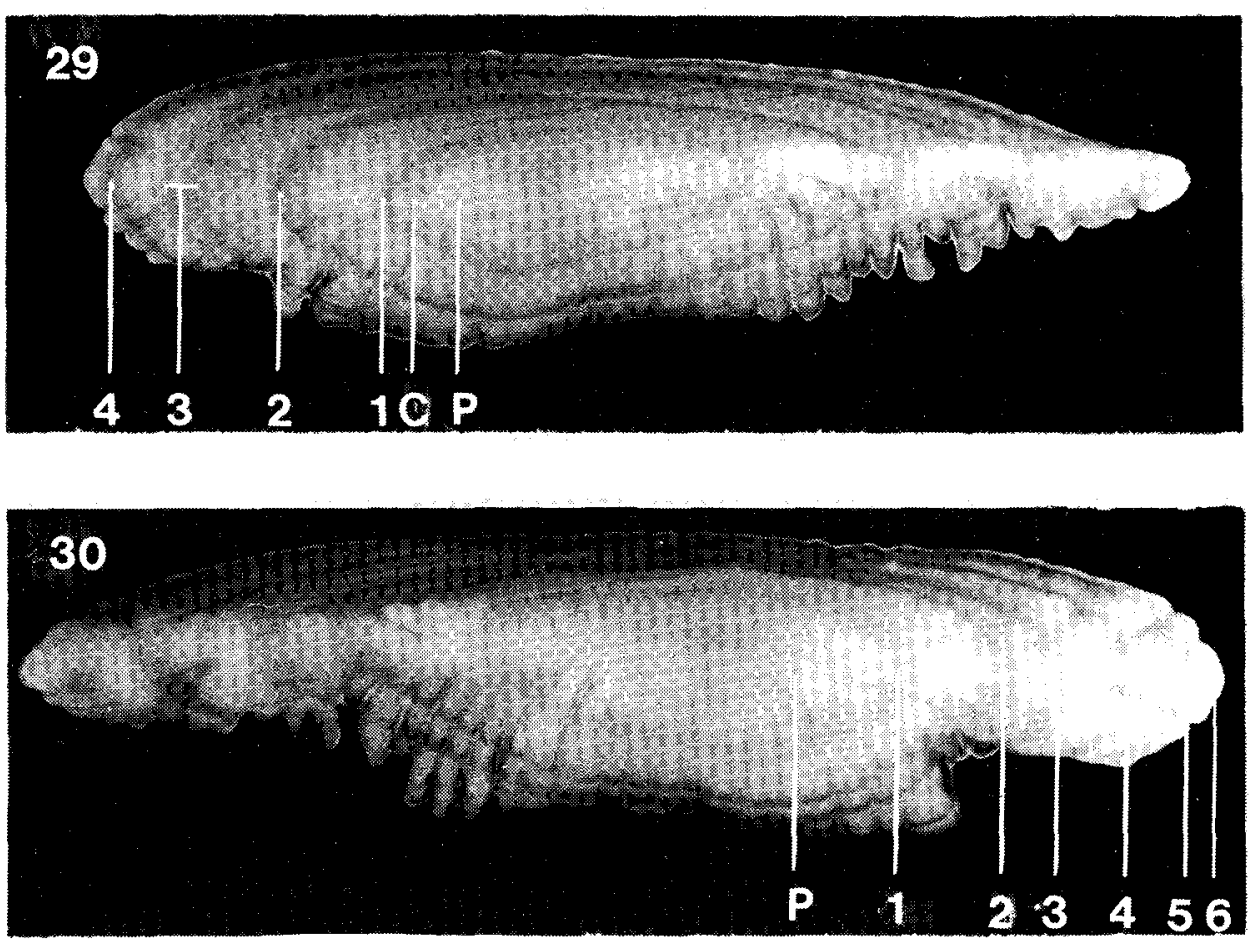
